\title{
The First Case of Jujube allergy presented as anaphylaxis in a child sensitized multiple food allergens: A case report
}

\section{Tae Seok Kang}

Kangwon National University College of Medicine: Kangwon National University School of Medicine Hana Kim

Kangwon National University School of Medicine

In Bum Suh

Kangwon National University School of Medicine

JaKyoung Kim ( $\square$ kjaky@kangwon.ac.kr)

Kangwon National University School of Medicine https://orcid.org/0000-0001-6724-3400

\section{Case report}

Keywords: Ziziphus, Food hypersensitivity, Cross reactions, Enzyme-Linked Immunosorbent Assay

Posted Date: March 1st, 2022

DOI: https://doi.org/10.21203/rs.3.rs-1348382/v1

License: (a) (i) This work is licensed under a Creative Commons Attribution 4.0 International License. Read Full License 
1 The First Case of Jujube allergy presented as anaphylaxis in a child sensitized multiple

2 food allergens: A case report

3 Tae Seok Kang, $\mathrm{MD}^{1}$, Hana Kim, $\mathrm{PhD}^{2}$, In Bum Suh, MD, $\mathrm{PhD}^{2}$, Ja Kyoung Kim, MD, PhD ${ }^{3}$

$4{ }^{1}$ Department of Family Medicine, College of medicine, Kangwon National University,

5 Chuncheon, Republic of Korea

$6{ }^{2}$ Department of Laboratory Medicine, Kangwon National University School of Medicine,

7 Chuncheon, Republic of Korea

$8{ }^{3}$ Department of Pediatrics, Kangwon National University School of Medicine, Chuncheon,

9 Republic of Korea

Short running title: Jujube allergy presented as anaphylaxis

Corresponding author: Ja Kyoung Kim, MD, Ph D

Department of Pediatrics, Kangwon National University School of Medicine,

Tel $+82-33-258-9020$

Fax $+82-33-258-2418$

\section{E-mail kjaky@kangwon.ac.kr}

\section{Abstract}

Background: Chinese jujube fruits, called daechu in Korea, have high nutritional and medical value and are consumed worldwide as fresh and dry fruit, but there are few reports of side effects or allergies. 
Case presentation: We present the first child's case, having anaphylaxis to this fruit in a patient with no latex allergy, but other food allergy such as pine nuts and kiwi. We took the examination using skin prick test specific immunoglobulin E ( $\operatorname{IgE}$ ) with unicap and indirect enzyme-linked immunosorbent assay (ELISA) to confirm the sensitization of the causative allergen. In the skin test, the result of latex and jujube was negative, and Unicap specific IgE tests for kiwi and pine nut were $2.34 \mathrm{kU} / \mathrm{L}$ and $2.87 \mathrm{kU} / \mathrm{L}$, and 0.55 O.D and 0.87 O.D (control group 0.36, 0.4) by indirect ELISA to kiwi and pine nut that we performed. The result of our performing indirect ELISA to jujube was positive as 0.62 O.D. (control group 0.41).

Conclusions: It is thought that research on allergenicity of jujube and the cross-relationship between jujube allergy antigen and food allergens such as kiwi or pine nut will be necessary in the future.

Keywords: Ziziphus, Food hypersensitivity, Cross reactions, Enzyme-Linked Immunosorbent Assay

\section{Background}

More than 600 species of jujube trees are grown in many parts of the world, and among them, Ziziphus jujuba Mill (Chinese jujube) and Z. mauritiana Lam. (Indian jujube or ber) are the most important with respect to distribution and economic significance. ${ }^{1}$ The fruit of the jujube tree has an oval shape, tastes like an apple with low acidity before it is ripe, and as it ripens, it turns red, wrinkled, and sweet. In many countries, the fruit of jujube is used as a snack, for cooking, and in medicine in its fresh or dried form. ${ }^{2}$ Jujube tree, which is cultivated in South Korea, is a species of Chinese jujube, and the fruit of the tree is called "Daechu" in Korean. It is not only used as medicine but also as a form of tea, unlike in other countries. ${ }^{3}$ Although Jujube fruits are used in various forms in many countries, there are next to no reports on jujube side-effect or allergy. However, in Taiwan, there was a report of jujube allergy which appeared 
as a cross antigen reaction from a patient with latex allergy ${ }^{4}$, and recently in Canada, anaphylaxis symptom due to jujube was reported in an adult without latex sensization ${ }^{5}$. Herein, we report a case of anaphylatic reaction to jujube in a child allergic to pine nuts and kiwi for the first time and suggest the possibility that jujube allergy could be induced by a cross reaction with other food allergies apart from latex.

\section{Case presentation}

A 9-year-old girl who had urticaria and respiratory discomfort after drinking jujube tea visited the outpatient pediatric clinic at Kangwon National University Hospital. Fifteen minutes after her mother started to boil jujube in a double boiler to make jujube tea, the patient began scratching around her back and neck. It then spread to the face and a red rash began to appear in the form of urticaria. After drinking some of the boiled jujube tea, her lips and eyelids began to swell and she found it difficult to breathe. Symptoms improved after injection therapy in the emergency room. The patient had taken dried jujube before, and there were no allergic symptoms such as urticaria at that time, and it was her first time having jujube tea. The patient had several types of food allergies, including egg white allergy before she was 1 year old, because of which she had a restricted diet and now shows no symptoms. In addition, the skin around her lips turned red after eating walnuts before, but she now does not show such symptoms and is able to eat walnuts. However, she had a history of treatment for severe urticaria, angioedema, and respiratory distress from both touching and eating pine nuts. She continues to show such symptoms even by just touching pine nuts and still refrains from eating pine nuts. Recently, a tingling mouth and red lips appeared after having a green kiwi, and similar symptoms appeared after having cherry. Often having itchy eyes and nose, she was diagnosed with asthma or allergic rhinitis, and the symptoms were severe enough to require treatment, especially in-between seasons. As for family history, she has a mother with allergic rhinitis symptoms. At the time of the hospital visit, there was no skin lesion of urticaria or angioedema 
detected during physical examination, and no abnormal findings such as wheezing on chest auscultation. To find causes of anaphylaxis, a blood test was performed to examine the number of eosinophils, the total density of immunoglobulin E ( $\operatorname{IgE})$, and any specific $\operatorname{IgE}$ test for egg white, pine nuts, walnut, and kiwi (Unicap, Pharmacia, Uppsala, Sweden). A skin prick test was performed using 40 standardized antigens (house dust mites, animal hair, tree, weed, lawn, latex (Lofarma, Milano, Italy)). From the result of the blood test, among 5,300/mm $\mathrm{m}^{3}$ leukocytes, the number of eosinophils was $190 / \mathrm{mm}^{3}$, and total $\mathrm{IgE}$ was $358.3 \mathrm{IU} / \mathrm{mL}$ (reference value, 1.5158.0). Specific IgE (Unicap F1) for egg white was $<0.35 \mathrm{kUA} / \mathrm{L}$, that for kiwi (Unicap F84) was $2.34 \mathrm{kUA} / \mathrm{L}$, that for pine nuts (Unicap F253) was $2.87 \mathrm{kUA} / \mathrm{L}$, and that for walnut (Unicap F256) was $<0.10 \mathrm{kUA} / \mathrm{L}$. From the skin prick test using standardized antigens, only Dermatophagoides farina (Df, $\mathrm{W}=7.5 \mathrm{~mm}$ ) showed a positive result by showing a bigger wheal size compared with that shown for histamine (histamine $1 \mathrm{mg} / \mathrm{mL}$, wheal size $(\mathrm{W})=4.5$ $\mathrm{mm} ; 0.9 \%$ saline, $\mathrm{W}=0 \mathrm{~mm}$ ) which was a positive control. In addition, Dermatophagoides pteronyssinus ( $\mathrm{Dp}, \mathrm{W}=4 \mathrm{~mm})$, Japanese alder, and Asian hazel ( $\mathrm{W}=2 \mathrm{~mm}$, respectively), white birch $(\mathrm{W}=3 \mathrm{~mm})$, beech $(\mathrm{W}=3.3 \mathrm{~mm})$, and kiwi $(\mathrm{W}=3.5 \mathrm{~mm})$ showed wheals even though they were smaller compared with those shown for histamine. Skin prick test result of latex, which is known to be associated with jujube allergy, was negative. Since there is no standardized antigen for jujube, the skin prick test was performed by prick-to-prick method using liquid obtained from brewing crushed jujube for over $30 \mathrm{~min}$ at $70^{\circ} \mathrm{C}$. The result was negative. (Figure 1).

To identify jujube-specific IgE from the serum of the patient, indirect enzyme-linked immunosorbent assay (indirect ELISA) was used. First, jujube, pine nuts, and kiwi were each ground with distilled water. The solutions were then serial distilled from 1:10 to $1: 10^{5}$ by 10 times each using bicarbonate buffer (pH 9.6). Approximately $100 \mathrm{uL}$ of each was dispensed into wells in the Nunc Maxisorb 96 well plate and cultured and attached at $4{ }^{\circ} \mathrm{C}$ overnight. To 
prevent a non-specific reaction, $100 \mathrm{uL}$ of blocking buffer (Blocker ${ }^{\mathrm{TM}} \mathrm{BSA}$ in phosphate buffered saline (PBS) (10×) Cat no. 37525, Thermo Fisher Scientific, Cleveland, OH, USA) was dispensed into each well, cultured at room temperature for $3 \mathrm{~h}$, and washed thrice by PBS. Serum from the patient and serum from negative control group that did not have a history of allergy were diluted, dispensed into each well $(100 \mathrm{uL})$, cultured for $1 \mathrm{~h}$, and washed thrice using PBS. Next, horseradish peroxidase (HRP)-conjugated IgE (Goat anti-Human IgE Secondary Antibody, HRP, Cat no. A18793, Invitrogen, Waltham, USA) was dispensed, cultured for $1 \mathrm{~h}$, and washed thrice using PBS. Approximately $50 \mathrm{uL}$ of tetramethylbenzidine (TMB; $1 \mathrm{mM}$ ), a chromogenic substrate, was added to each well and maintained for $10 \mathrm{~min}$ and the reaction was terminated by adding $50 \mathrm{uL}$ of $\mathrm{H}_{2} \mathrm{SO}_{4}(2 \mathrm{M})$. Next, the absorbance (O.D., Optical Density) of each well was measured at $450 \mathrm{~nm}$ using a spectrophotometer (SpectraMax ${ }^{\circledR}$ ABS Plus, Molecular Devices, CA, USA). Results demonstrated that the IgE for jujube in the serum of the patient was 0.62 O.D., which was higher than 0.33 and 0.42 O.D. found in the control group (Table 1).

Symptoms of the patient were diagnosed as an anaphylaxis by jujube-specific immunoglobulin E mediated reaction. Because pine nuts and kiwi allergies were found from both the medical history and blood tests, instructions were given to avoid eating jujube, pine nuts and kiwi. Epinephrine auto-injector was prescribed after giving instructions on how to use it. Also, we will plan the allergen immunotherapy to house dust mite and birch, if she has persistent moderate to severe symptoms of allergic rhinitis, and to observe if there is to disappear its symptom to jujube after it or not.

\section{Discussion and Conclusions}

There was previously a report on jujube allergy caused by latex-fruit syndrome ${ }^{4}$, and a recent report of IgE-mediated anaphylaxis without latex sensitization in an adult ${ }^{5}$; however, our study is the first to report an anaphylaxis induced by jujube via IgE-mediated immune response in a 
child. In addition, unlike previous reports that were about allergy symptoms by Indian jujube (Z. mauritiana), this study is the first to report about Chinese jujube (Z. jujuba Mill). More specifically, allergic symptoms to antigen released in vapor form were detected in a child, who did not eat jujube often but had a history of anaphylaxis or oral allergy symptoms from allergy to certain foods such as kiwi and pine nuts.

To confirm that Chinese jujube was the cause of anaphylaxis symptoms in the patient, IgE was measured using a skin prick test and indirect ELISA from serum. Because there was no commercially available skin prick test reagent, the skin prick test was performed by the prick-to-prick method and the result was negative (Fig 1). In addition, as the result from the skin prick test to examine the reaction to latex was negative, it was concluded that there was no sensitization to latex. However, from the indirect ELISA test, not only was the jujube-specific IgE measured at a similar density as that for pine nuts or kiwi, which induced allergic symptoms in the patient, but also at a significantly higher density compared with that in the control group (Table 1). Although an oral challenge for food allergy diagnosis was not performed, it was assumed that the patient had an IgE-mediated allergic reaction to jujube.

Plant food allergen is classified by structure or biological function of the protein. Antigens that are taxonomically different but have homologous structures may cause cross reactions leading to allergic symptoms such as pollen-fruit, latex-fruit cross-reactive syndrome, and celery-mugwort-spice syndrome, among others. Allergic symptoms-inducing components could be seed-storage proteins, enzyme activity or proteins which work as defense system against other living creature such as pathogenesis-related proteins (PRs). ${ }^{7}$ In a Taiwanese report on a patient with latex allergy who showed allergy symptoms to Indian jujube, the main allergen was Ziz m 1 (30 KD), which is similar to plant class III chitinase which works as PRs ${ }^{8,9}$. This report showed that symptoms could have appeared in the patient with latex allergy by cross reaction. ${ }^{4}$ 
However, although the patient in our study showed sensitization to kiwi and pine nuts from the skin prick test and clinically, the result from the skin prick test to latex was negative, this implied a chance of cross reaction of symptom-inducing Chinese date with components of kiwi or pine nuts. Particularly in the case of an adult patient in $\mathrm{Canada}^{5}$, who often had Indian jujube as dessert but did not take it at all after moving to Canada, symptoms appeared after reintake after a certain period of time. The skin prick test for jujube was positive, which suggested induction of allergy symptom by sensitization to jujube itself without sensitization to other antigens. However, the patient in our study did not take jujube or jujube tea often, and symptoms appeared by inhaling antigen while boiling jujube tea, implying a possibility of cross reaction with other food antigens. Clinical symptoms, Unicap test results, and indirect IgE test results showed that Chinese jujube may have cross reacted with pine nuts rather than with kiwi. Until now, there has been no report of allergy antigenicity for Chinese date that induced symptoms in the patient in our study. Inferring from the research on how Indian jujube and Chinese jujube are taxonomically similar but have different structural composition or biological functions due to differences in environment ${ }^{10}$, there must be differences in allergens as well. Although there is no report on jujube allergy in South Korea, in the national large-scale survey research on patients with pollen food allergy syndrome ${ }^{11}, 8.9 \%$ had jujube allergy symptoms, and jujube accounted for $15.9 \%$ of food antigens that induced symptoms by cross reaction with tree pollen. Also, in terms of correlation between aeroallergen and food antigens, jujube showed a high correlation with chestnut and showed higher correlation with pine nut than with kiwi, suggesting that symptoms from the patient in this study could be induced by cross reaction with other foods or aeroallergens.

Therefore, future research should be focused on identifying antigen proteins of Chinese jujube and investigating whether it has cross-reactivity with other food items such as pine nuts or other aeroallergens. 
170

171

172

173

174

175

176

177

178

179

180

181

182

183

184

185

186

187

188

\section{List of abbreviations}

ELISA: Enzyme-linked immunosorbent assay

HRP: Horseradish peroxidase

Ig E: Immunoglobulin E

O.D.: Optical density

PBS: Phosphate buffered saline

PRs: Pathogenesis-related proteins

TMB: Tetramethylbenzidine

W: Wheal size

\section{Declarations}

Ethics approval and consent to participate

This study was approved by the Institutional Review Board of Kangwon National University Hospital (KNUH-2021-05-003). As a retrospective case report, written consent was waived.

\section{Consent for publication}

Written informed consent for publication of their clinical details and clinical image was obtained from the patient and parent regardless of the approval of the institutional review board of our hospital.

Availability of date and materials

Not applicable

Competing interests 
190

191

192

193

194

195

196

197

198

199

200

201

202

203

204

205

206

207

208

209

210

211

The authors have no potential conflicts of interest to disclose.

\section{Funding}

This work was not supported by any foundation.

Authors' contributions

Kang TS contributed to this work as first authors. Author contributions are as followed: Conceptualization: Kim JK. Investigation: Kim H and Suh IB. Writing - original draft: Kang TS. Writing - review \& editing: Kim JK. All authors read and approved the final manuscript.

\section{Acknowledgements}

Not applicable

\section{References}

1. J.P. Sheng, L. Shen. 13-Chinese jujube (Zizipus jujube Mill.) and Indian jujube (Zizipus mauritiana Lam.). In: Elhadi M. Yahia, editor. Postharvest biology and technology of tropical and subtropical fruits. $1^{\text {st }}$ ed. Cambridge, United Kingdom: Woodhead Publishing; 2011, 299-325.

2. Jujube.

https://terms.naver.com/entry.nhn?docId=1081530\&cid=40942\&categoryId=32816. Accessed December 22, 2020

3. Jujube. https://en.wikipedia.org/wiki/Jujube. Updated 2020, Accessed December 22, 2020

4. Lee MF, Chen YH, Lan JL, Tseng CY, Wu CH. Allergenic components of Indian jujube (Zizyphus mauritiana) show IgE cross-reactivity with latex allergen. Int Arch Allergy Immunol. 2004;133:211-6.

5. Aberumand B, Borici-Mazi R. A rare case of anaphylaxis to Indian jujube (Ziziphus 
Mauritiana Lam). Allergy Asthma Clin Immunol. 2020;16:48.

213

214

215

216

217

218

219

220

221

222

223

224

225

6. Ahn KM. Classification and character of plant food allergens. Pediatr Allergy Respir Dis. $2007 ; 17: 1-7$

7. Breiteneder H, Radauer C. A classification of plant food allergens. J Allergy Clin Immunol. 2004;113:821-30.

8. Lee MF, Hwang GY, Chen $\mathrm{YH}$, Lin $\mathrm{HC}$, Wu CH. Molecular cloning of Indian jujube (Zizyphus mauritiana) allergen Ziz m 1 with sequence similarity to plant class III chitinases. Mol Immunol. 2006;43:1144-1151.

9. Leoni C, Volpicella M, Dileo M C.G., Gattulli B A.R., Ceci L R. Chitinases as food allergens. Molecules. 2019;24:2087.

10. Gul S, Duan J, Li Y, Wang R, Yan H, Qian D, Tang Y, Su S. Comparison of the bioactive components in two seeds of Zizipus species by different analytic approaches combined with chemometrics. Front Pharmacol. 2017;8:609.

11. Kim MA, Kim DK, Yang HJ, Yoo Y, Ahn Y, Park HS, et al. Pollen-food allergy syndrome in Korean pollinosis patients: A nationwide survey. Allergy Asthma Immunol Res. 2018;10:648-661. 


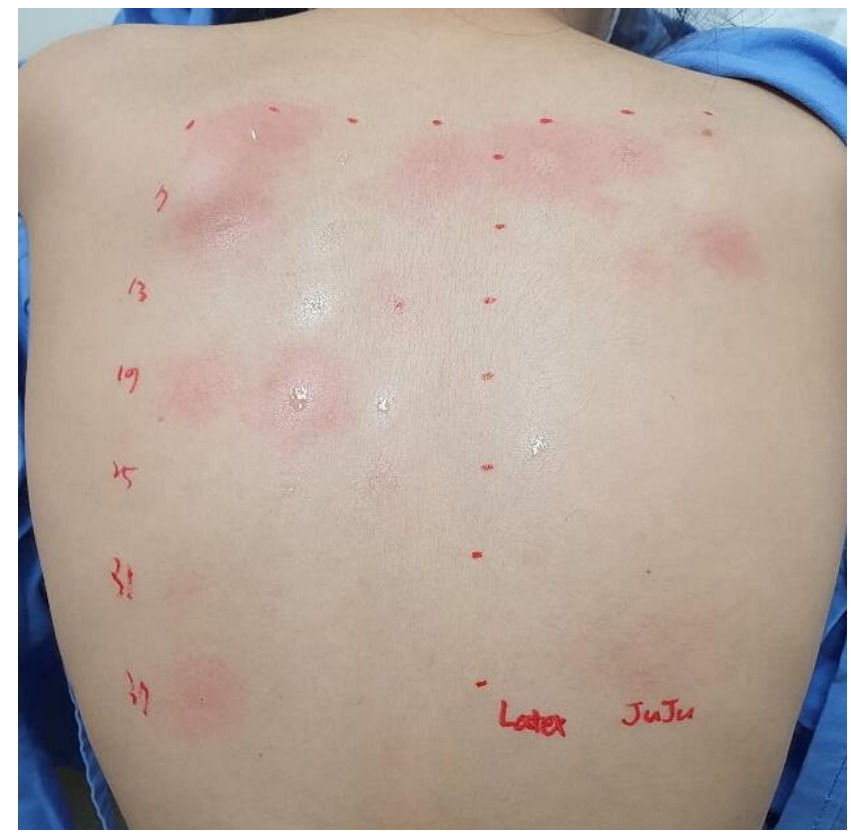

229 Figure 1. Skin prick test and prick to prick test of jujube.

230 After crushing the dried jujube, it was infused in water at $70^{\circ} \mathrm{C}$ for 30 mins and the water was 231 used for a prick-to-prick test. Wheal and flare reaction was found by house dust mites, tree 232 pollens, and kiwi, and latex and jujube showed a negative reaction. 
233 Table 1. Results of Indirect ELISA to confirm Ig E to Jujube in this patient

\begin{tabular}{cccc}
\hline Classification & Jujube (O.D.) & Pine nut (O.D.) & Kiwi (O.D.) \\
\hline Patient & 0.62 & 0.87 & 0.55 \\
Control 1 & 0.33 & 0.30 & 0.36 \\
Control 2 & 0.42 & 0.50 & 0.40
\end{tabular}

234 ELISA, enzyme-linked immunosorbent assay; Ig, immunoglobuline; O.D., optical density 